\title{
Three-Dimensional Microstructural Characterization of Bulk \\ Plutonium and Uranium Metals Using Focused Ion Beam Technique
}

\author{
Brandon W. Chung*, Robert G. Erler, and Nick E. Teslich \\ Lawrence Livermore National Laboratory \\ P.O. Box 808, Livermore, CA 94551, USA
}

\begin{abstract}
Nuclear forensics requires accurate quantification of discriminating microstructural characteristics of the bulk nuclear material to identify its process history and provenance. Conventional metallographic preparation techniques for bulk plutonium $(\mathrm{Pu})$ and uranium (U) metals are limited to providing information in two-dimension (2D) and do not allow for obtaining depth profile of the material. In this contribution, use of dualbeam focused ion-beam/scanning electron microscopy (FIB-SEM) to investigate the internal microstructure of bulk Pu and $\mathrm{U}$ metals is demonstrated. Our results demonstrate that the dual-beam methodology optimally elucidate microstructural features without preparation artifacts, and the three-dimensional (3D) characterization of inner microstructures can reveal salient microstructural features that cannot be observed from conventional metallographic techniques. Examples are shown to demonstrate the benefit of FIB-SEM in improving microstructural characterization of microscopic inclusions, particularly with respect to nuclear forensics.
\end{abstract}

*Corresponding author - Tel.: 1925 4233896; fax: 19254242491 ; e-mail: chung7@1lnl.gov

$1 / 36$

(C) 2016. This manuscript version is made available under the Elsevier user license http://www.elsevier.com/open-access/userlicense/1.0/ 


\section{Introduction}

Nuclear forensics requires acquiring information inherent to nuclear materials to determine their process history and provenances. Typical nuclear materials are either subjected to technological processing or are entirely of anthropogenic origin [1-6]. It is generally known that nuclear materials are produced in multi-step processes in specialized and dedicated operations $[2,7,8]$. It is generally assumed that various

processing parameters impart characteristic morphological features. Consequently, nuclear materials carry certain characteristic features associated with processes they were subjected to. Using these salient characteristics, one can narrow down the possible process history and provenances of nuclear materials. While there have been significant radiochemistry work to evaluate characteristics such as isotopic compositions and trace elements $[2-4,6,7,9-28]$, there is dearth of investigative effort into the microstructural characteristics that are dictated by their chemical and metallurgical processes, as well as by the chemical species present in the processing environment in contact with nuclear materials.

Among various forms of nuclear materials, bulk plutonium (Pu) and uranium (U) metals are the materials of primary concern to nuclear forensics. While there is significant work being performed on oxides and intermediate products of $\mathrm{Pu}$ and $\mathrm{U}$ materials, there are very limited studies on bulk forms of Pu and $\mathrm{U}$ metals. These bulk metals will have discriminating microstructural features imparted by their production processes and provenances, particularly from trace impurities or chemical additions. Thus, it is imperative to preserve the sample's integrity and evidentiary microstructural features for proper nuclear forensics. However, the published studies have typically 
performed in the context of metallurgical research using microstructural characterization methods that are not suited for nuclear forensics.

Historically, metallographic preparation and characterization of bulk $\mathrm{Pu}$ and $\mathrm{U}$ metals have been tailored to investigate specific microstructural features [1, 5, 29, 30]. Some examples of microstructural characteristics are grain shape and size distribution, inclusions, secondary phases, and pores. It is very crucial to preserve these characteristics when preparing specimens for evaluation. The quality of microstructural characterization is highly dependent on the metallographic sample preparation. Conventional preparation processes, where the specimen must be cut, mounted, ground, polished, and chemically etched are tailored to reveal specific microstructural features. However, the resulting microstructures can be complicated by damage introduced during polishing and etching processes (Figure 1). Furthermore, only two-dimensional (2D) images from the processed surface can be measured which do not represent the exact nature of material features within the bulk [31-38]. These 2D images provide overall microstructural views but certain microstructural features may be obscured. There are a number of microstructural parameters such as feature connectivity, size, and shape that cannot be inferred from traditional 2D imaging techniques. These shortcomings prevent accurate measurements of important microstructural features in bulk $\mathrm{Pu}$ and $\mathrm{U}$ metals for a credible microstructural interpretation relevant to nuclear forensics.

The focused ion beam (FIB) instrument uses ions to sputter the surface of a sample to expose sub-surface features $[35,37,39,40]$. This process largely eliminates chemical etching marks, mechanical polishing artifacts, and process contaminants inherent to conventional metallographic sample preparations. This FIB technique allows 
for obtaining high-fidelity microstructure and morphology of the sampled volume. While the FIB microscopy has been used for decades in various analytical applications and proven to be an indispensable analytical tool in materials science [31, 33, 35, 37, 39-45], it has not been applied to highly radioactive materials such as $\mathrm{Pu}$ and $\mathrm{U}$ metals. We have been evaluating applicability of the FIB-SEM instrument (FEI DualBeam Quanta 3D FEG) to improve quantification of key microstructural features entrained in bulk Pu and $\mathrm{U}$ metals. The aim of this paper is to point out improvements in analyzing microstructural characteristics of bulk Pu and U metals using the FIB technique and benefits of threedimensional (3D) microscopy for nuclear forensics.

\section{Experimental}

High-resolution FIB-SEM microscope FEI DualBeam Quanta 3D was used for 2D and 3D microstructural characterizations. This instrument consists of electron column with field emission gun (FEG) and focused ion column containing gallium $(\mathrm{Ga})$ ion source. For FIB-SEM analysis, specimens of Pu and $\mathrm{U}$ metals were prepared in glove boxes approved for radiological materials to control the spread of contamination. To minimize

surface damage, specimens were sectioned with a low speed diamond saw, mounted in an epoxy, and mechanically polished. After the mechanical polishing step, each specimen was mounted on a SEM stub and placed on a sample holder, which was needed to access the necessary tilt angles for the serial-sectioning experiment. The mounted specimen was then inserted into the FIB-SEM DualBeam instrument. Although details such as the handling radiological sample in the microscope are specific to this work, it is likely that the general FIB-SEM DualBeam operational techniques are applicable. 
A focused Ga-ion beam was used to surface mill the Pu and $\mathrm{U}$ metal specimens.

During the milling operation of the bulk metal specimen, the ion beam energy and current were set between 8 to $30 \mathrm{kV}$ and 15 nanoAmp (nA), respectively. After this, fine milling was performed with $0.1 \mathrm{nA}$ beam current. Surface milled specimen was imaged in electron induced SEM mode (e-SEM) from the normal direction. Ion beam induced (iSEM) images were acquired from either the normal direction by tilting or the direction parallel to the cross-section plane.

A serial-sectioning technique often referred as "slice and view" was applied to acquire a series of internal microstructural images or slices to create a data set for 3D reconstruction. First the sample volume-of-interest is initially prepared as shown in Figure 2(a). The sample has been quickly FIB milled planar to the surface at $30 \mathrm{kV}$ and $0.1 \mathrm{nA}$ to reveal site specific microstructural features prior to the serial-sectioning experiment. Pt cap layer is deposited over the sampling volume using the ion beam to protect the surface of the volume interrogated during FIB's milling process as shown in Figure 2(b). The standard serial-sectioning procedure begins by rough milling a U-shaped trench in the sample at $30 \mathrm{kV}$ and 15 microAmp $(\mu \mathrm{A})$. This high-beam current was chosen to reduce the total sputter time to less than 10 minutes in a typical milling preparation process. One wall of the trench is vertical and becomes the initial crosssection imaged by SEM as shown in Figure 2(c). After the initial preparation, fine milling for each slice was performed with $30 \mathrm{kV}$ and $0.1 \mathrm{nA}$ beam current to remove a predetermined thickness of material from this wall. Each cross-sectional slice was imaged in electron induced SEM mode (e-SEM) from the 52 degree tilted direction that is normal to the FIB column. This process is iterated until the cross-section advances through the 
targeted volume. The sequence of 2D images or slices acquired at each step is then combined to construct 3D representation of the probed sample volume.

\section{Results}

Ion milling capability of FIB-SEM is used to prepare planar surfaces of $\mathrm{Pu}$ and $\mathrm{U}$ metals. As can be seen in Figures 3 and 4, e-SEM images taken on ion milled surfaces show relatively low surface damage compared to conventional methods, revealing microstructural features without preferential removal of materials along the grain boundaries and from within the grains. It appears there is a small, yet observable, preferred milling process that depends on the nature of the material causing topological roughness on the surface. The images also reveal surface scratches that likely formed from the handling or cutting processes to harvest the specimen in glove boxes. With FIB milling at higher Ga-ion energy, these surface scratches are readily removed but can cause severe damage to the remaining bulk of the material.

Both e-SEM and i-SEM imaging modes demonstrate the benefit of the FIB technique in preserving material features that are normally removed in conventional methods shown in Figure 1. In the same manner that images are generated in the conventional SEM, the ion beam from FIB can be rastered over a sample surface and emitted secondary electrons can be detected for imaging. Figure 5 shows the e-SEM image of Pu metal and the associated i-SEM image. While there are several contrast mechanisms by ion induced secondary electrons in FIB microscopy [40, 43], our preliminary work indicates that the i-SEM image in Figure 5(b) shows the material contrast produced by ion-induced secondary electrons. The i-SEM imaging mode reveals increased image contrast (or brightness) from a region containing microscopic inclusions from impurities along the 
grain boundaries and within the grains. Using the electron probe microanalysis, we determined that these inclusions contain iron impurity (likely forming the low melting eutectic $\left.\mathrm{Pu}_{6} \mathrm{Fe}[1]\right)$, with a trace of nickel and chromium, present along the grain boundaries and carbon within the grains. It is apparent from this image that the yield of ion-induced secondary electrons is higher with lower atomic number elements, and the contrast arises from differences in specimen chemistry. Here we have direct evidence showing that FIB milling can preserve material features imparted from trace impurities or chemical additions. In comparison, traditional metallographic preparation processes (Figure 1) are ill suited to uncovering hard-to-prepare microstructures like sample composed of both soft and hard materials including microscopic inclusions. Figure 6 shows e-SEM and i-SEM images of electrolytically prepared Pu specimen. We can see that the etching process reveals grain features with clearly defined grain boundaries as previously seen in Figure 1 from optical metallography. However, the i-SEM image reveals lack of the material contrast due to the preferential removal of impurity materials or inclusions along the grain boundaries and within the grains. Problems associated with these traditional techniques include etch pitting and the loss of inclusions. Results shown in Figures 5 and 6 confirm that FIB milling can better preserve materials that are easily etched out in traditional electrolytic etching processes.

The main advantage of FIB-SEM is an ability to reveal the microstructure in threedimension (3D). Figure 7 shows some representative sequence of 2D images or slices acquired from the specimen shown in Figure 2. It contains $\mathrm{Pu}_{6} \mathrm{Fe}$ inclusions, a carbide inclusion, and pores within the probed sample volume. Data for this reconstruction is obtained from 295 slices, which are spaced apart in depth at intervals of approximately 
$0.024 \mu \mathrm{m}$. When experimental data acquisition is complete, the dataset is reconstructed using Amira Visualization software to 3D representation. Different colors are assigned to various impurity-derived materials embedded within the Pu metal. Thereby the Pu matrix (grains) is set transparent so that the complex microstructure of the microscopic inclusions becomes visible. Our 3D representation shows extensive distribution of the low melting eutectic compound $\mathrm{Pu}_{6} \mathrm{Fe}$ strung out along the internal grain boundaries between Pu grains and a carbide inclusion. Unlike the conventional 2D micrographs, 3D representation provides us with 3D information of the probed volume, such as real shape, size, and distribution of microstructural features. To the best of our knowledge, this is the first report of manipulating bulk Pu metals in this way for cross-sectioning to generate $3 \mathrm{D}$ internal microstructural features that are normally etched out using conventional preparation methods.

Figure 8 shows 3D representation of internal microstructural features in a Pu metal containing various impurity materials and pores. This experiment acquired a total of 160 cross-sectional slices, which are spaced approximately $0.1 \mu \mathrm{m}$ between each image slice. Figure 8(a) shows some representative sliced images. This particular Pu metal contains high concentration of carbide inclusions and pores. Some pores are nearly few microns in size. The likely cause of the pore formation is due to the difference in thermal expansion coefficient between carbide inclusions and the Pu metal during solidification from the melt $\left(640^{\circ} \mathrm{C}\right)$ to room temperature. Interestingly the compound $\mathrm{Pu}_{6} \mathrm{Fe}$ is also strung out along the grain boundaries and formed within the pores around carbide inclusions. The connectivity between these microstructural features is nearly impossible to discern without the aid of 3D representation shown in Figure 8(b). 
Figure 9 shows 3D representation of a $U$ metal containing a carbide inclusion acquired from 400 cross-sectioned slices, which are spaced apart at intervals of approximately $0.023 \mu \mathrm{m}$. It shows carbide inclusion wedged between $U$ grains. Unlike the electrolytically etched U metal shown in Figure 1 or the 2D SEM image in Figure 9(a), we can clearly see the true microstructural features of a carbide inclusion embedded between U grains.

\section{Discussion}

The FIB technique presented here for bulk Pu and U metals offers advantages over earlier conventional metallographic preparation techniques and microstructural characterization. This technique combined with microstructural imaging capability of SEM (DualBeam capability) permits relatively low damage milling process that preserves samples that include both soft and hard materials that would tend to adulterate easily by conventional preparations. Furthermore, this capability allows for precision microsurgery by ion milling to expose inner microstructures and more accurate 3D quantification of microstructural features that have been elusive using conventional 2D imaging techniques.

The FIB-SEM technique shown here demonstrates significant improvement in representation of microstructural features of bulk $\mathrm{Pu}$ and $\mathrm{U}$ metals that go beyond the gross average values measured by conventional methods. We have shown FIB milling significantly eliminates the adulteration of $\mathrm{Pu}$ and $\mathrm{U}$ metals normally seen when using conventional metallographic preparations (Figures 5 and 6). While it is not possible to 
avoid all damages to the specimen surface when ions are used; damages can be minimized through careful choices of FIB operational parameters.

Additionally, we can take advantage of images formed by i-SEM to locate microscopic impurity materials or inclusions embedded in Pu and U metals. Our study shows increase in the yield of ion-induced secondary electrons from the lighter atomic number elements than $\mathrm{Pu}$ or $\mathrm{U}$, resulting in higher contrast (brightness) from microscopic inclusions containing lighter impurity elements. This material contrast arises from differences in the yield of secondary electrons as a function of specimen chemistry [40, 43]. Thus, FIB secondary electron image (i-SEM) can reveal minute entrained microscopic inclusions or material heterogeneities that are not normally revealed in the conventional SEM imaging. This i-SEM mode provides us with complementary information in local variations of material features.

The higher-quality microstructural characterization can be extracted by $3 \mathrm{D}$ microscopy using the precision sectioning and imaging process known as the "slice and view" technique (Figures 7-9) [37, 46, 47]. For the first time, the 3D microscopy reveals the exact nature of some key features of microscopic inclusions residing within bulk $\mathrm{Pu}$ and $\mathrm{U}$ metals. Our work shows the precise location and distribution of impurity-derived microscopic inclusions within inner microstructures. These materials are distributed extensively with complex morphological features within the bulk and provide us with clues to their processing history. For example, consider the presence and location of carbide inclusions within the bulk $\mathrm{Pu}$ and $\mathrm{U}$ as revealed in 3D microscopy. These evidentiary features point to the possible use of carbon-containing equipment (e.g. graphite mold, crucible, etc) during the melt processing of Pu and $\mathrm{U}$ metals. The 
distribution of pores around carbides indicates the Pu metal solidified in a follow-up process. The difference in thermal expansion between the carbide and the Pu metal probably caused micro-cracks and seen as pores around carbides. Presence of iron-based inclusions within the bulk $\mathrm{Pu}$, with a trace of nickel and chromium, indicates likely contamination from stainless steel tools or equipment. The processing conditions probably favored the iron impurity forming the low-melting eutectic compound $\mathrm{Pu}_{6} \mathrm{Fe}$ [1]. The $\mathrm{Pu}_{6} \mathrm{Fe}$ probably segregated to and strung out along the grain boundaries or pores during the solidification of $\mathrm{Pu}$ or other processing conditions above $428^{\circ} \mathrm{C}$.

For application in nuclear forensics, it is imperative that we preserve discriminating microstructural features which betray materials' processes and provenances. Microstructural characteristics such as grain shape and size distribution, inclusions, secondary phases, and pores are some evidentiary examples for nuclear forensics. The impact of using the FIB-SEM technique to nuclear forensics to extract and evaluate entrapped material signatures is very evident from this work, where we see for the first time the exact nature of microstructural morphology, including inner microstructural features, in $\mathrm{Pu}$ and $\mathrm{U}$ metals that have been elusive. Furthermore, FIB milling can be used to reveal materials or microstructural features residing under the exposed surface layer. Considering that both $\mathrm{Pu}$ and $\mathrm{U}$ metals are very reactive to various environments, it will be a great benefit to be able to remove the adulterated surface layer for more accurate microstructural characterization. Rather than identifying discriminating microstructural features by highly idealized and a priori known conventional 2D microstructural images, the FIB technique allows for high-fidelity quantification of microstructural features for nuclear forensics. 
From the examples in this paper, we demonstrated application of the FIB technique as a potent tool in sample preparation and microstructural characterization for highly radioactive and surface reactive $\mathrm{Pu}$ and $\mathrm{U}$ metals. Based on the past work on the development and application of FIB in several areas of materials science $[31,33,35,37$, $39-43,45]$, there is still significant work to be done. There is still more work to evaluate the dependence of FIB operational parameters to the quality of the microstructural image. Operational parameters such as ion beam and sample orientation, beam raster speed, voltage, and current settings may require further tuning for optimization. The quality of 3D reconstruction is directly related to the SEM image quality of the sliced images. The drift and charging from the epoxy mount and $\mathrm{Pu}$ should be minimized to improve the SEM image quality. This work showed the material contrast produced by ion-induced secondary electrons in i-SEM. Further work should be performed to evaluate the dependence of i-SEM imaging with other contrast mechanisms such as crystallographic orientation (channeling) and topography [40,43]. We need to improve 3D visualization and analysis to quantify microstructural features to metrics that cover fundamental parameters such as size, shape, connectivity, and distribution. For example, how do we describe and quantify the $\mathrm{Pu}_{6} \mathrm{Fe}$ strung out along grain boundaries? The ability to accurately analyze 3D microstructural features in a full 3D environment can help to narrow down the possible production history and provenance of the nuclear material. This data can complement the isotopic and chemical data to improve nuclear forensic conclusions. As described in other work [31, 35-37, 39, 44], it will be extremely beneficial for nuclear forensics to couple the FIB technique with crystallographic, chemical, and surface analysis techniques. Combination of these techniques will allow 
for simultaneous acquisition of complex chemical and structural data of microstructural features.

\section{Conclusions}

The FIB-SEM technique shows several advantages over conventional metallographic sample preparations and analysis of bulk Pu and $\mathrm{U}$ metals. Polishing artifacts are largely eliminated. FIB milling better preserves materials that are normally etched out in electrolytic polishing and etching processes. More importantly, the precise sectioning and imaging with SEM allow for 3D microscopy of inner microstructures, revealing salient microstructural features that cannot be observed from conventional metallographic techniques. Selected examples clearly show microscopic inclusions are distributed extensively with complex morphology within bulk $\mathrm{Pu}$ and $\mathrm{U}$ metals. The data provides insights into their processing conditions with relevance to improving nuclear forensics and understanding metallurgical process-property relationship. FIB-SEM is a potent analytical tool for complex characterization of nuclear materials that cannot be readily characterized in 2D using standard microscopy. This technique shows potential to improve 3D description of microstructure in terms of site specificity for more accurate and quantitative analysis for nuclear forensics.

\section{Acknowledgments}

This work performed under the auspices of the U.S. Department of Energy by Lawrence Livermore National Laboratory under Contract DE-AC52-07NA27344. This work received partial support from the U.S. Department of Homeland Security, Domestic 
Nuclear Detection Office. This support does not constitute an expressed or implied endorsement on the part of the Government. 
References[1] S. S. Hecker, Los Alamos Science 26 (2000) 290.

[2] K. Mayer, M. Wallenius and Z. Varga, Chemical Reviews 113 (2013) 884.

[3] K. Mayer, M. Wallenius and T. Fanghaenel, Journal of Alloys and Compounds 444 (2007) 50.

[4] K. Mayer, M. Wallenius and I. Ray, Analyst 130 (2005) 433.

[5] O. J. Wick, ed., Plutonium Handbook: A Guide to the Technology (American Nuclear Society, La Grange Park, IL, 1980).

[6] K. Mayer, M. Wallenius, K. Lutzenkirchen, J. Galy, Z. Varga, N. Erdmann, R. Buda, J. V. Kratz, N. Trautmann, K. Fifield and Iop, in "International Nuclear Physics Conference 2010" (Iop Publishing Ltd, Bristol, 2010).

[7] K. J. Moody, P. M. Grant and I. D. Hutcheon, Nuclear Forensic Analysis (CRC Press, Boca Raton, FL, 2015).

[8] D. L. Clark, S. S. Hecker, G. D. Jarvinen and M. P. Neu, in "The Chemistry of the Actinide and Transactinide Elements", edited by L. R. Morss, N. M. Edelstein and J. Fuger (Springer, 2006) p. 813.

[9] M. Wallenius, K. Luetzenkirchen, K. Mayer, I. Ray, L. A. I. d. 1. Heras, M. Betti, O. Cromboom, M. Hild, B. Lynch, A. Nicholl, H. Ottmar, G. Rasmussen, A. Schubert, G. Tamborini, H. Thiele, W. Wagner, C. Walker and E. Zuleger, Journal of Alloys and Compounds 444 (2007) 57.

[10] M. Wallenius and K. Mayer, Fresenius Journal of Analytical Chemistry 366 (2000) 234.

[11] M. Wallenius, K. Mayer and I. Ray, Forensic Science International 156 (2006) 55.

[12] M. Wallenius, A. Morgenstern, C. Apostolidis and K. Mayer, Anal. Bioanal.

Chem. 374 (2002) 379.

[13] M. Wallenius, P. Peerani and L. Koch, Journal of Radioanalytical and Nuclear Chemistry 246 (2000) 317.

[14] M. Wallenius, G. Tamborini and L. Koch, Radiochimica Acta 89 (2001) 55.

[15] K. Mayer, M. Wallenius, M. Hedberg and K. Luetzenkirchen, Radiochimica Acta 97 (2009) 261.

[16] Y. Miyamoto, D. Suzuki, F. Esaka and M. Magara, Anal. Bioanal. Chem. 407 (2015) 7165.

[17] A. Morgenstern, C. Apostolidis and K. Mayer, Analytical Chemistry 74 (2002) 5513.

[18] G. Nicolaou, Journal of Environmental Radioactivity 99 (2008) 1708.

[19] U. Nygren, H. Rameback and C. Nilsson, Journal of Radioanalytical and Nuclear Chemistry 272 (2007) 45.

[20] L. Pajo, K. Mayer and L. Koch, Fresenius Journal of Analytical Chemistry 371 (2001) 348 .

[21] S. Richter, A. Alonso-Munoz, R. Eykens, U. Jacobsson, H. Kuehn, A. Verbruggen, Y. Aregbe, R. Wellum and E. Keegan, International Journal of Mass Spectrometry 269 (2008) 145.

[22] Z. Varga and G. Suranyi, Analytica Chimica Acta 599 (2007) 16.

[23] Z. Varga and G. Suranyi, Applied Radiation and Isotopes 67 (2009) 516.

[24] S. P. LaMont and G. Hall, Journal of Radioanalytical and Nuclear Chemistry 264 (2005) 423.

[25] R. P. Keegan and R. J. Gehrke, Applied Radiation and Isotopes 59 (2003) 137. 
[26] Y. Chen, Z.-y. Chang, Y.-g. Zhao, J.-l. Zhang, J.-h. Li and F.-j. Shu, Journal of Radioanalytical and Nuclear Chemistry 281 (2009) 675.

[27] D. Alamelu and S. K. Aggarwal, International Journal of Nuclear Energy Science and Technology 630.

[28] U. Admon, D. Donohue, H. Aigner, G. Tamborini, O. Bildstein and M. Betti, Microscopy and Microanalysis 11 (2005) 354.

[29] J. N. Mitchell, F. E. Gibbs, T. G. Zocco and R. A. Pereyra, Metallurgical and Materials Transactions A 32A (2001) 649.

[30] A. M. Kelly, D. J. Thoma, R. D. Field, P. S. Dunn and D. F. Teter, Journal of Nuclear Materials 353 (2006) 158.

[31] H. Chen, V. H. Grassian, L. V. Saraf and A. Laskin, Analyst 138 (2013) 451.

[32] M. D. Uchic, M. A. Groeber, D. M. Dimiduk and J. P. Simmons, Scripta Materialia 55 (2006) 23.

[33] Y. Z. Wang, R. W. Revie, M. W. Phaneuf and J. Li, Fatigue \& Fracture of Engineering Materials \& Structures 22 (1999) 251.

[34] M. D. Uchic, M. De Graef, R. Wheeler and D. M. Dimiduk, Ultramicroscopy 109 (2009) 1229.

[35] P. G. Kotula, G. S. Rohrer and M. P. Marsh, MRS Bulletin 39 (2014) 361.

[36] M. Cantoni and L. Holzer, Mrs Bulletin 39 (2014) 354.

[37] M. D. Uchic, L. Holzer, B. J. Inkson, E. L. Principe and P. Munroe, MRS Bulletin 32 (2007) 408.

[38] N. Antoniou, K. Rykaczewski and M. D. Uchic, MRS Bulletin 39 (2014) 347.

[39] U. Admon, in "Radioactive Particles in the Environment" (Springer, Dordrecht, 2009) p. 15.

[40] M. W. Phaneuf, Micron 30 (1999) 277.

[41] A. Aitkaliyeva, J. W. Madden, B. D. Miller and J. I. Cole, Micron 67 (2014) 65.

[42] C. A. Volkert and A. M. Minor, MRS Bulletin 32 (2007) 389.

[43] D. C. Joy and J. R. Michael, MRS Bulletin 39 (2014) 342.

[44] J. M. Conny, Environmental Science \& Technology 47 (2013) 8575.

[45] B. D. Miller, J. Gan, J. Madden, J. F. Jue, A. Robinson and D. D. Keiser, J. Nucl. Mater. 424 (2012) 38.

[46] J. E. Spowart, Scripta Materialia 55 (2006) 5.

[47] S. Cao, W. Tirry, W. Van Den Broek and D. Schryvers, J. Microsc.. 233 (2009)

61. 


\section{Figure Captions}

Figure 1. Example optical micrographs of $\mathrm{Pu}$ and $\mathrm{U}$ metals showing preparation artifacts caused by mechanical and electrolytic preparations: mechanical polishing of (a) Pu and (b) U metals, and electrolytic etching of (c) Pu and (d) U metals. Mechanical polishing performed on a vibratory polishing wheel causes surface scratches and inclusion pull-out. Electrolytic processes using ethlylene glycol (90\%) - nitric acid (10\%) solution preferentially remove materials along grain boundaries and cause etch pittings seen as dark lines and spots, respectively.

Figure 2. FIB operation to prepare volume-of-interest from a Pu metal for "slice and view" operation: (a) Selected sampling area indicated by the white circle, (b) deposited Pt protective layer over the sampling area, and (c) cross-sectioned trench operation.

Figure 3. Effects of FIB milling on the surface of Pu metal at different Ga-ion energy: (a) $8 \mathrm{kV}$ and (b) $30 \mathrm{kV}$. FIB milling performed at 16 nanoAmp, 1 microsecond raster, and 52 degree. e-SEM images taken after 4 minutes of FIB milling

Figure 4. Effects of FIB milling on the surface of U metal at different Ga-ion energy: (a) $8 \mathrm{kV}$ and (b) $30 \mathrm{kV}$. FIB milling performed at 12 nanoAmp, 12 microsecond raster, and 52 degree. e-SEM images taken after 30 seconds of FIB milling

Figure 5. Images of Pu metal surface by (a) e-SEM and (b) i-SEM. The ion-induced secondary electrons offer strong material contrast from differences in the yield of secondary electrons as a function of specimen chemistry. 
Figure 6. Images of electrolytically prepared Pu metal surface by (a) e-SEM and (b) iSEM. The i-SEM image shows lack of the material contrast due to the preferential removal of microscopic inclusions by the electrochemical etching process.

Figure 7. 3D inner microstructures of a Pu metal: (a) Some representative crosssectioned slices from the volume-of-interest. Sampled cross-sections show material features from pores, carbide inclusion and iron-impurity inclusions. (b) Two different perspective views of a 3D reconstruction of impurities and pores contained within the volume-of-interest: carbide (red), pore (purple), $\mathrm{Pu}_{6} \mathrm{Fe}$ (yellow), and $\mathrm{Pu}$ (transparent). The frame around the 3D representation measures $10 \mu \mathrm{m} \times 10 \mu \mathrm{m} \times 10 \mu \mathrm{m}$.

Figure 8. 3D inner microstructures of a $\mathrm{Pu}$ metal containing various impurities: (a) Some representative cross-sectioned slices, and (b) two different 3D perspective views of the inner microstructures. (c) 3D reconstruction shows very complex distribution and shapes of material features caused by its production process: carbide (red), pore (purple), $\mathrm{Pu}_{6} \mathrm{Fe}$ (yellow), and $\mathrm{Pu}$ (transparent). The frame around the 3D representation measures $16 \mu \mathrm{m} \times 16$ $\mu \mathrm{m} \times 10 \mu \mathrm{m}$.

Figure 9. 3D inner microstructures of a U metal: (a) Selected sampling area (white circle) with a carbide inclusion by e-SEM. (b) 3D reconstruction of the sampled volume from 400 cross-sectioned slices. 3D representation of the selected sampling volume revealing a carbide inclusion (red) embedded 
between $\mathrm{U}$ grains (multi-colors). The frame around the 3D representation measures $15 \mu \mathrm{m} \times 16 \mu \mathrm{m} \times 15 \mu \mathrm{m}$. 


\section{Polishing scratches}
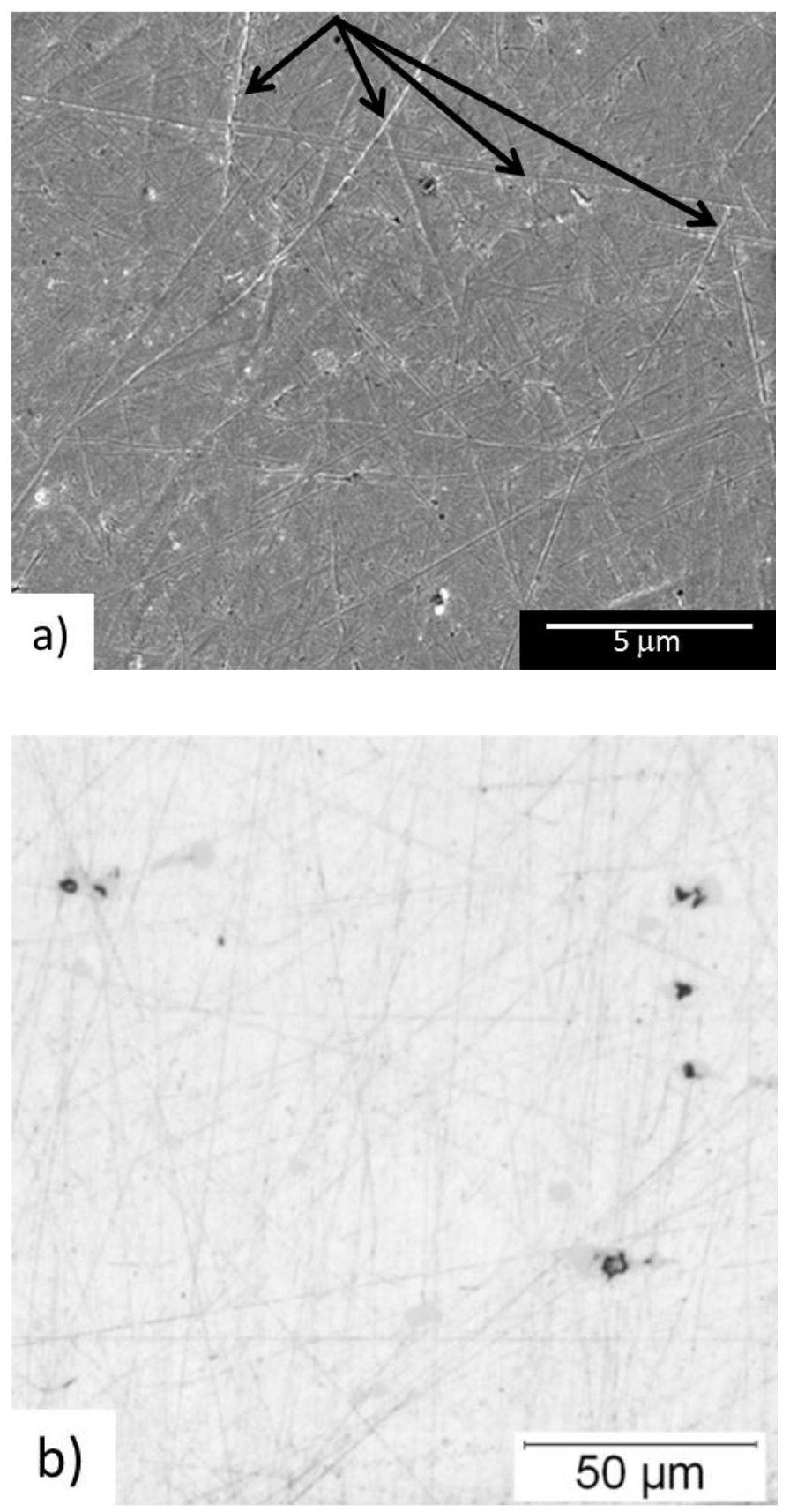

Figure 1 (a and b) 

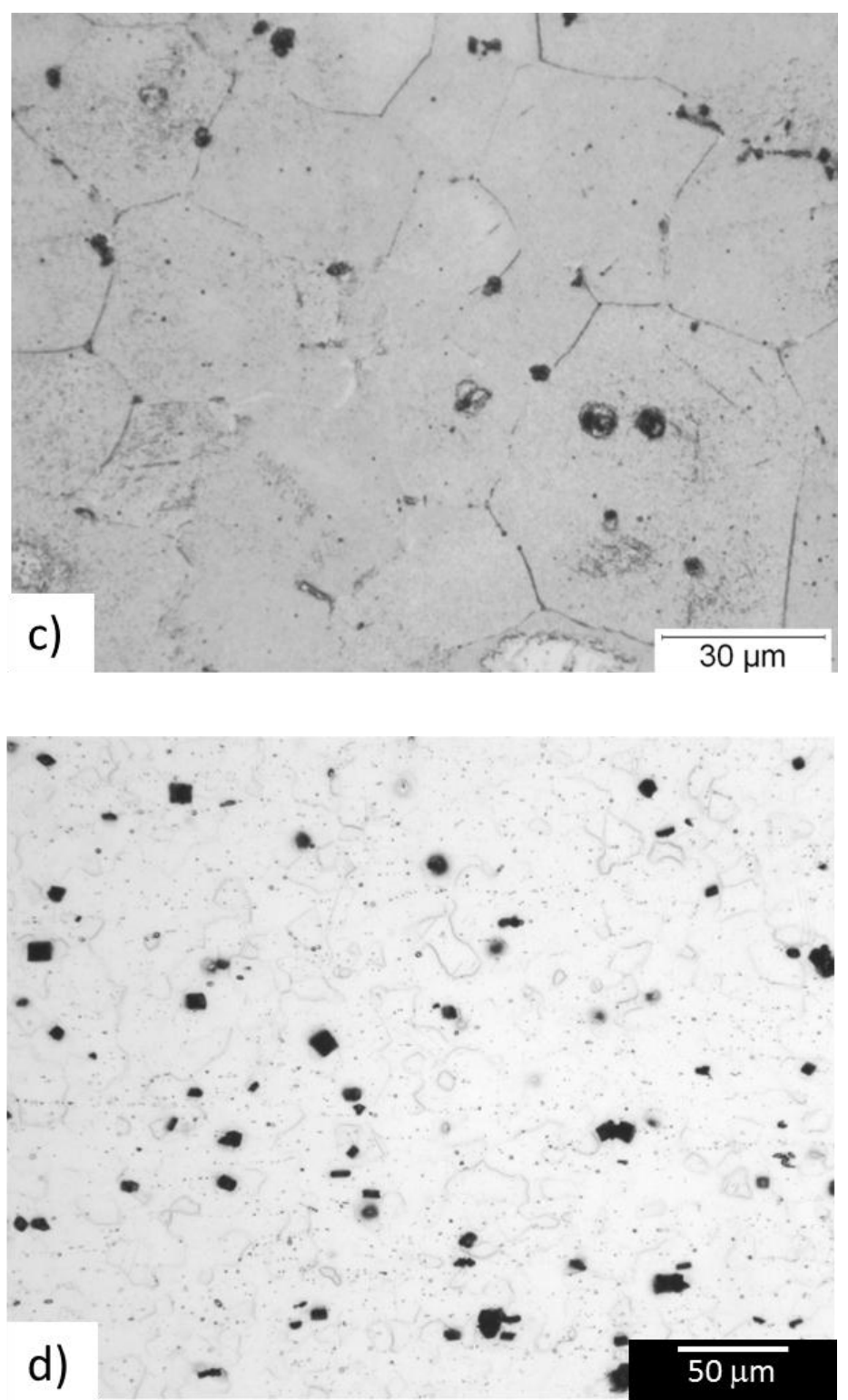

Figure 1 (c and d) 

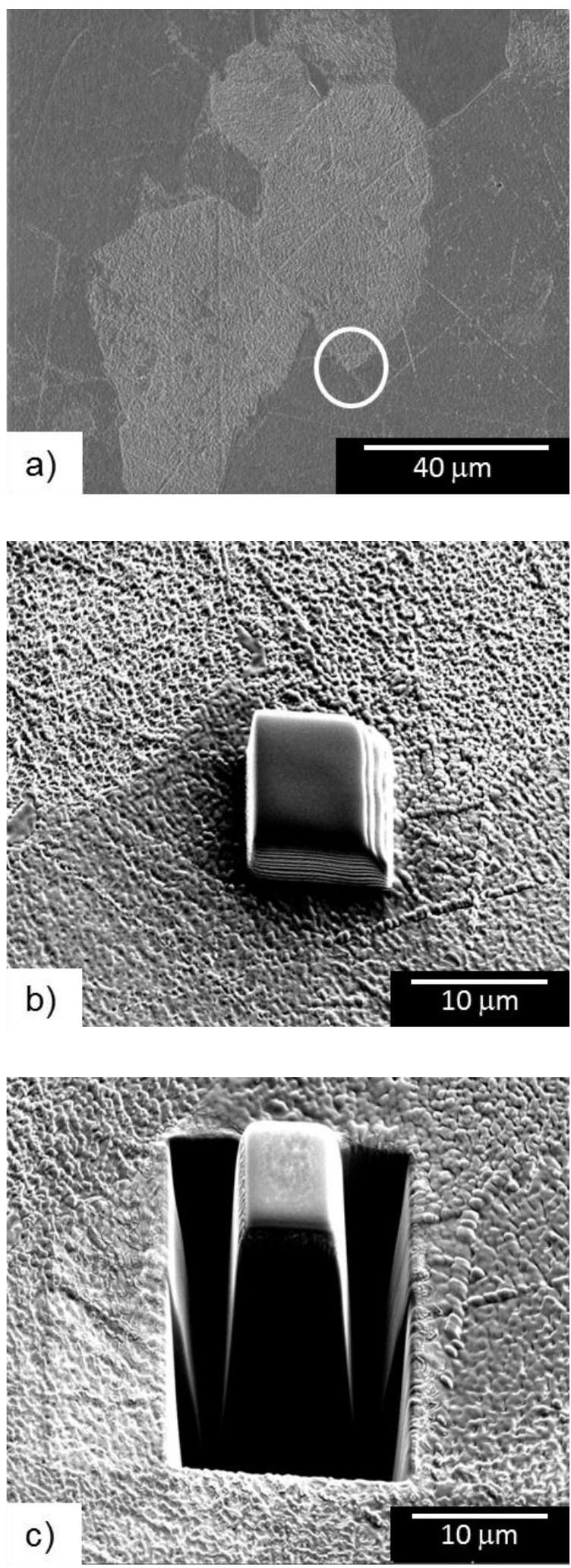

Figure 2 


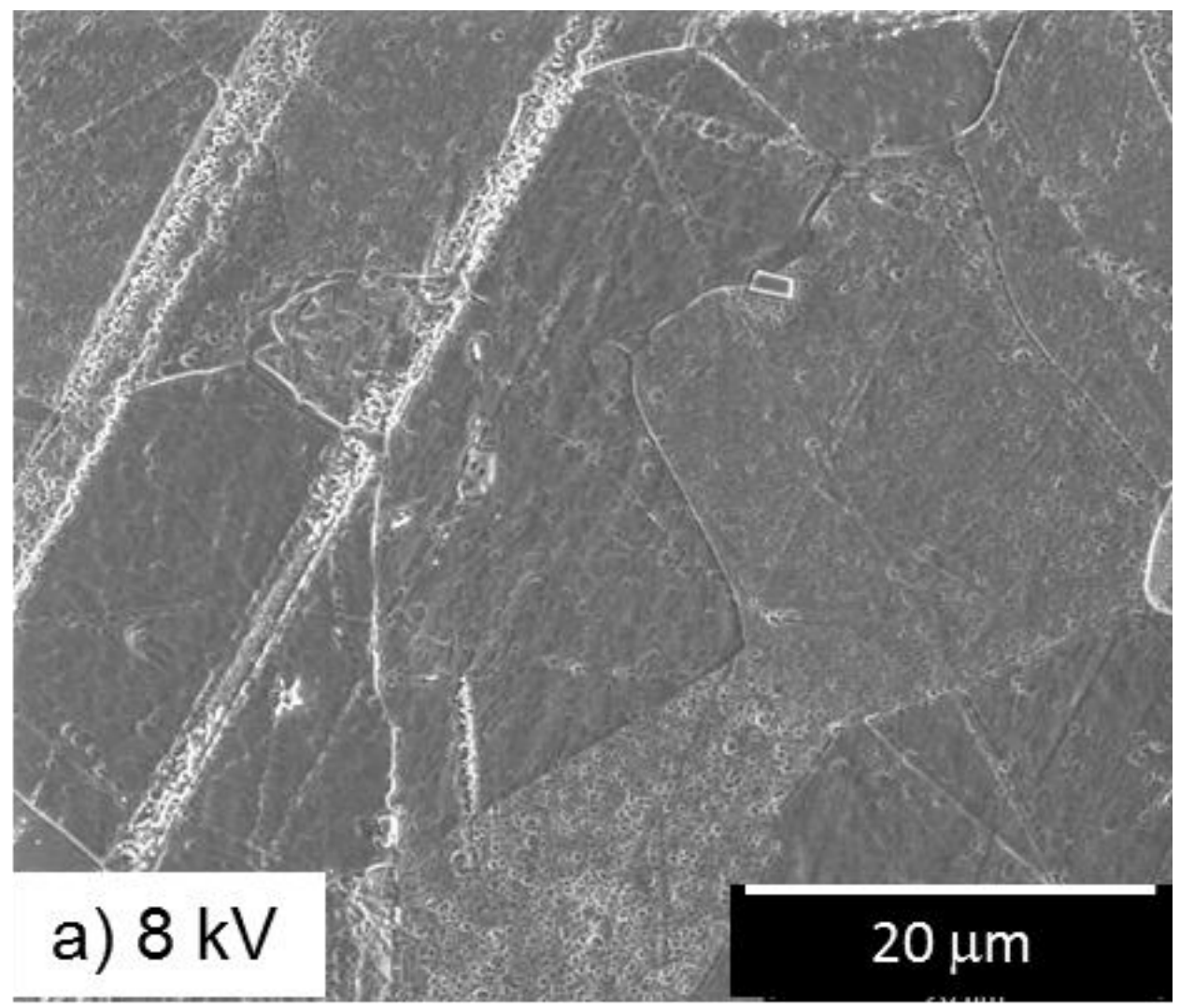

Figure 3(a) 


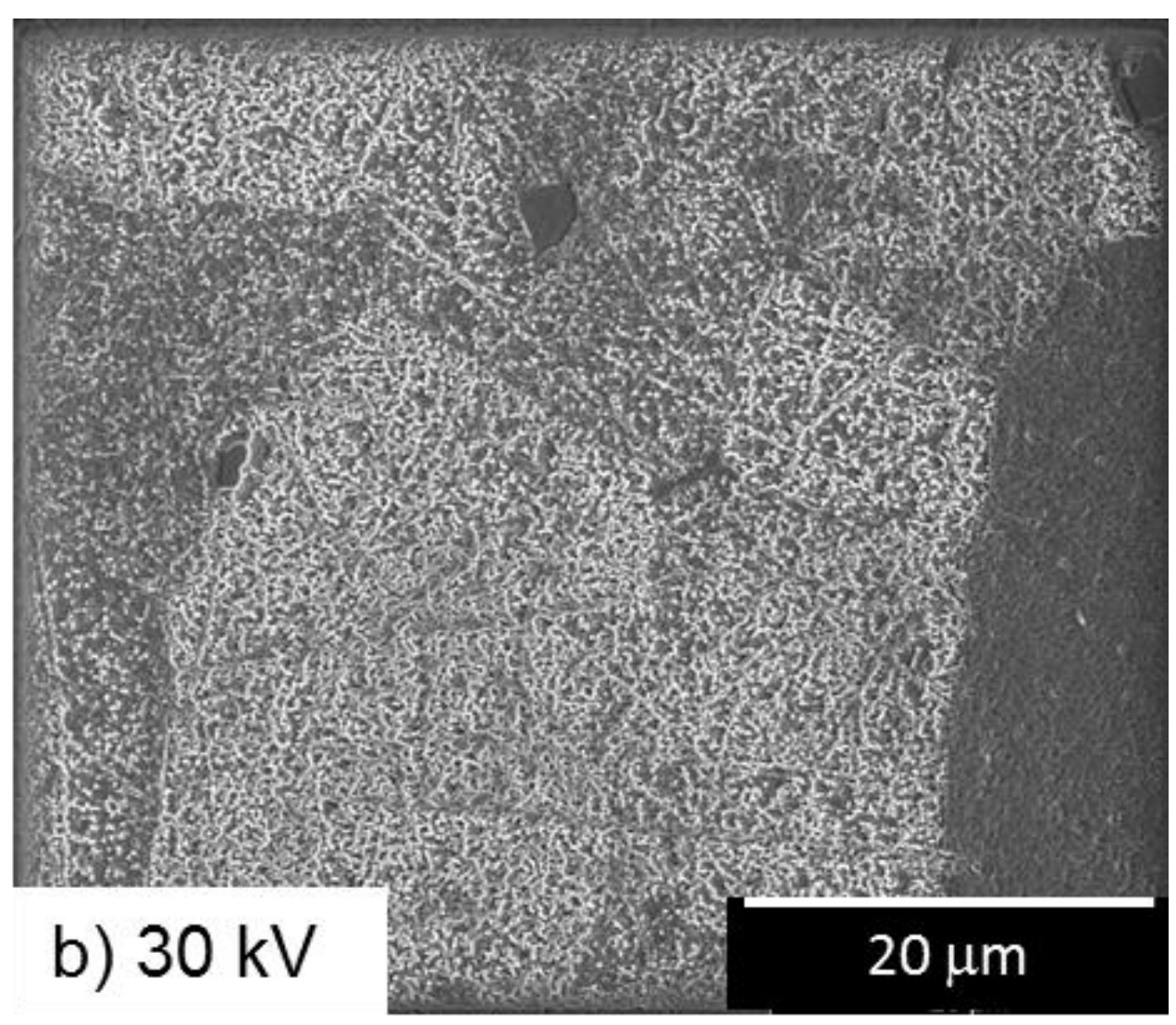

Figure 3(b) 


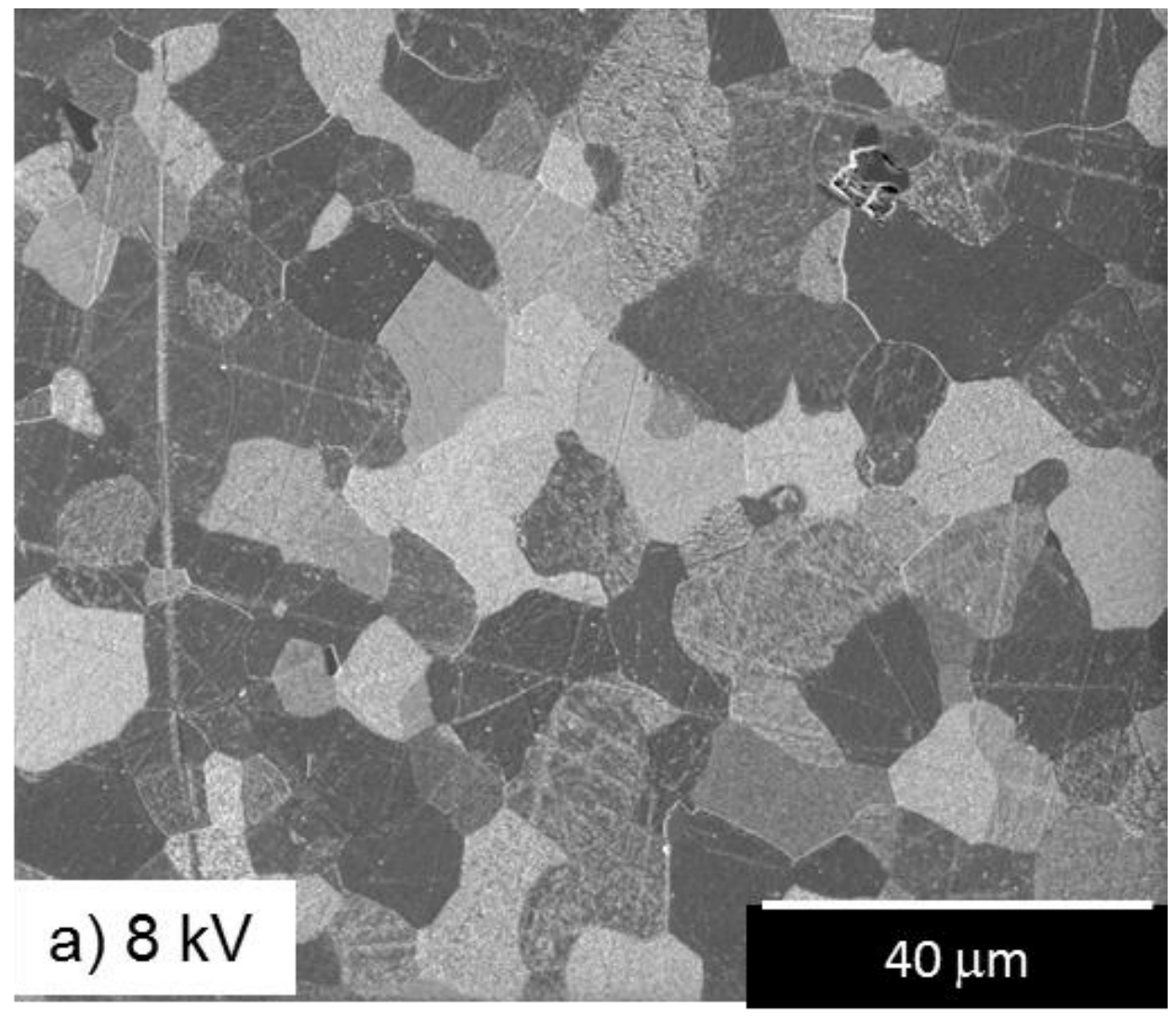

Figure 4(a) 


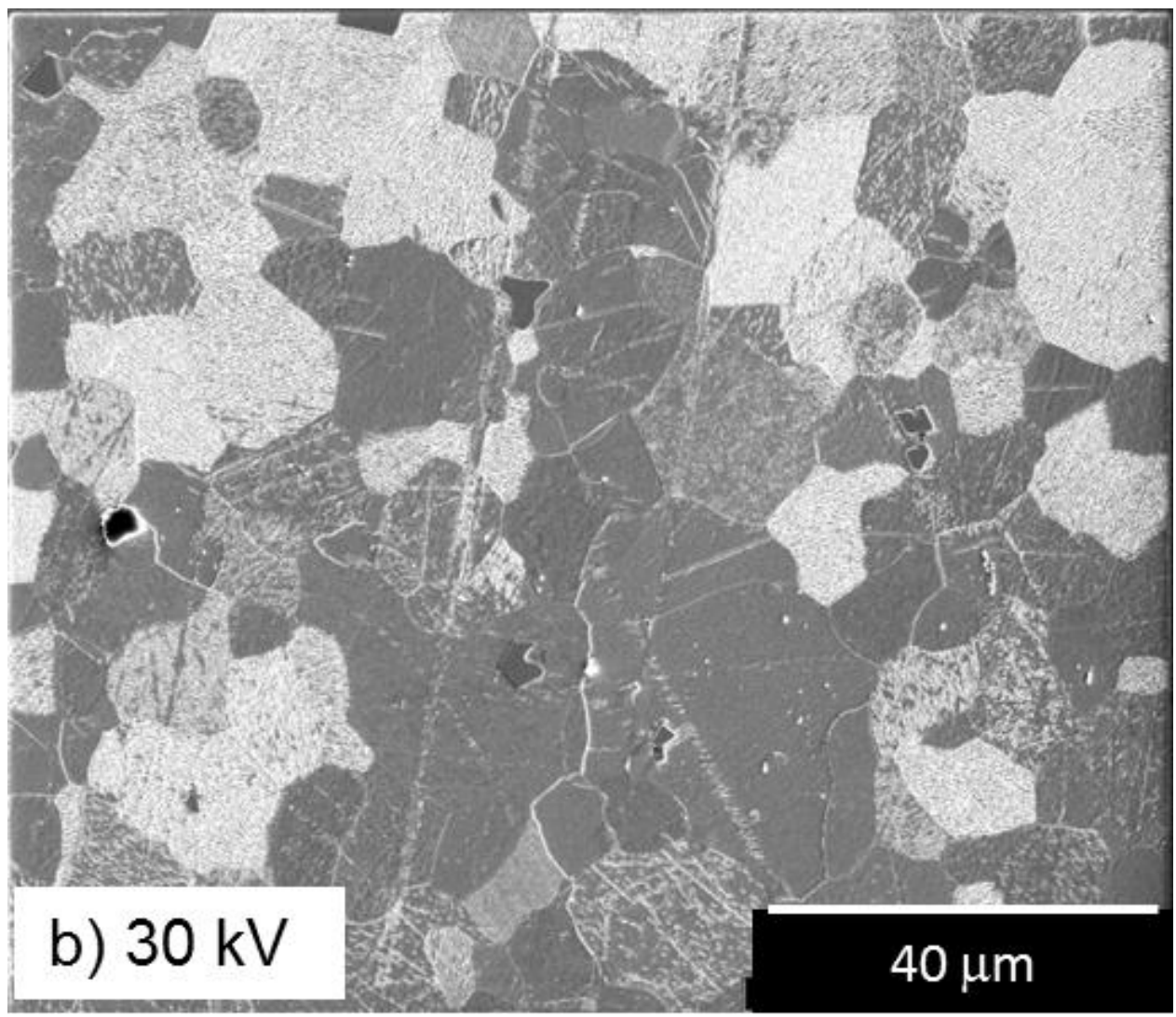

Figure 4(b) 


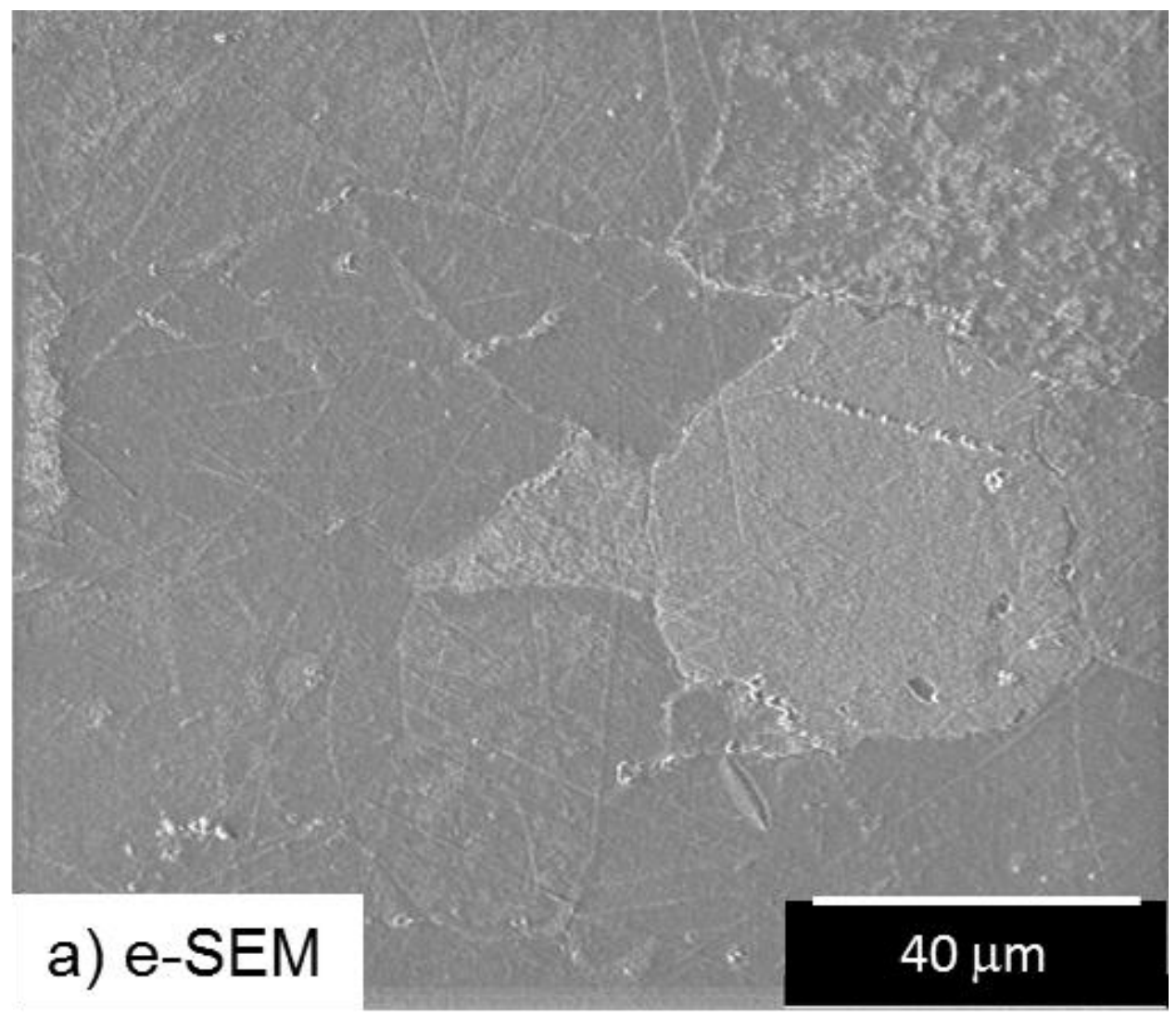

Figure 5(a) 


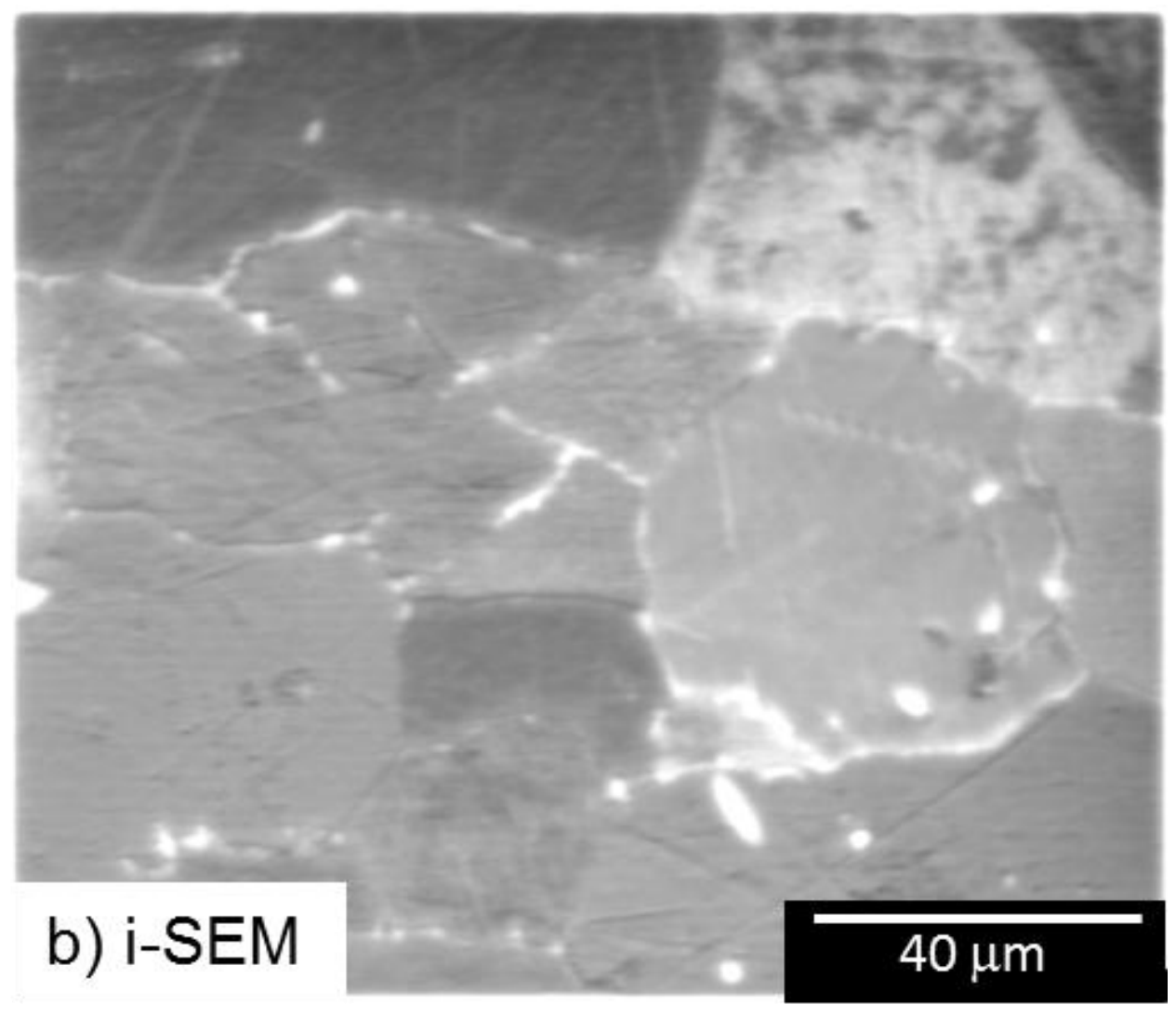

Figure 5 (b) 


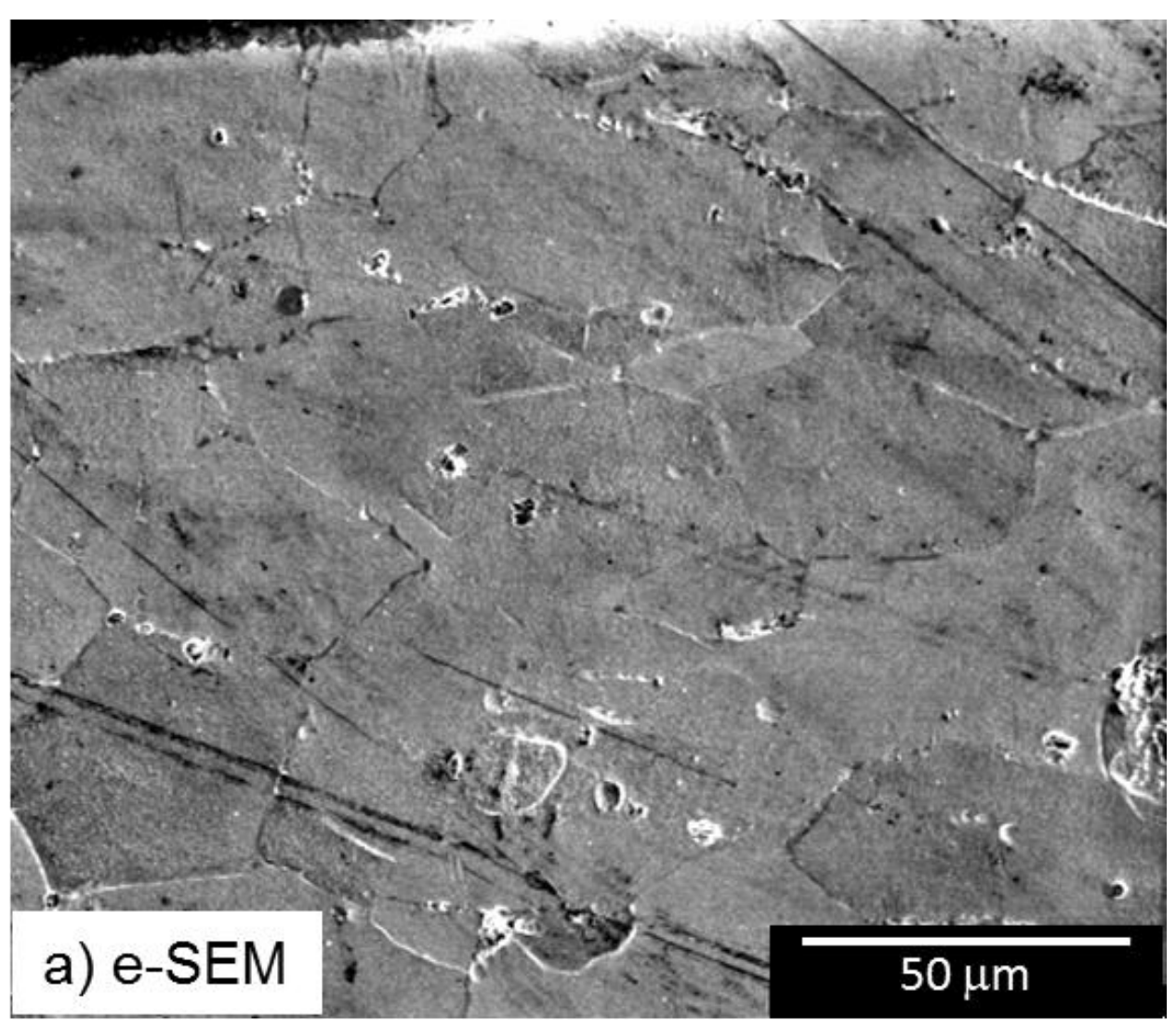

Figure 6 (a) 


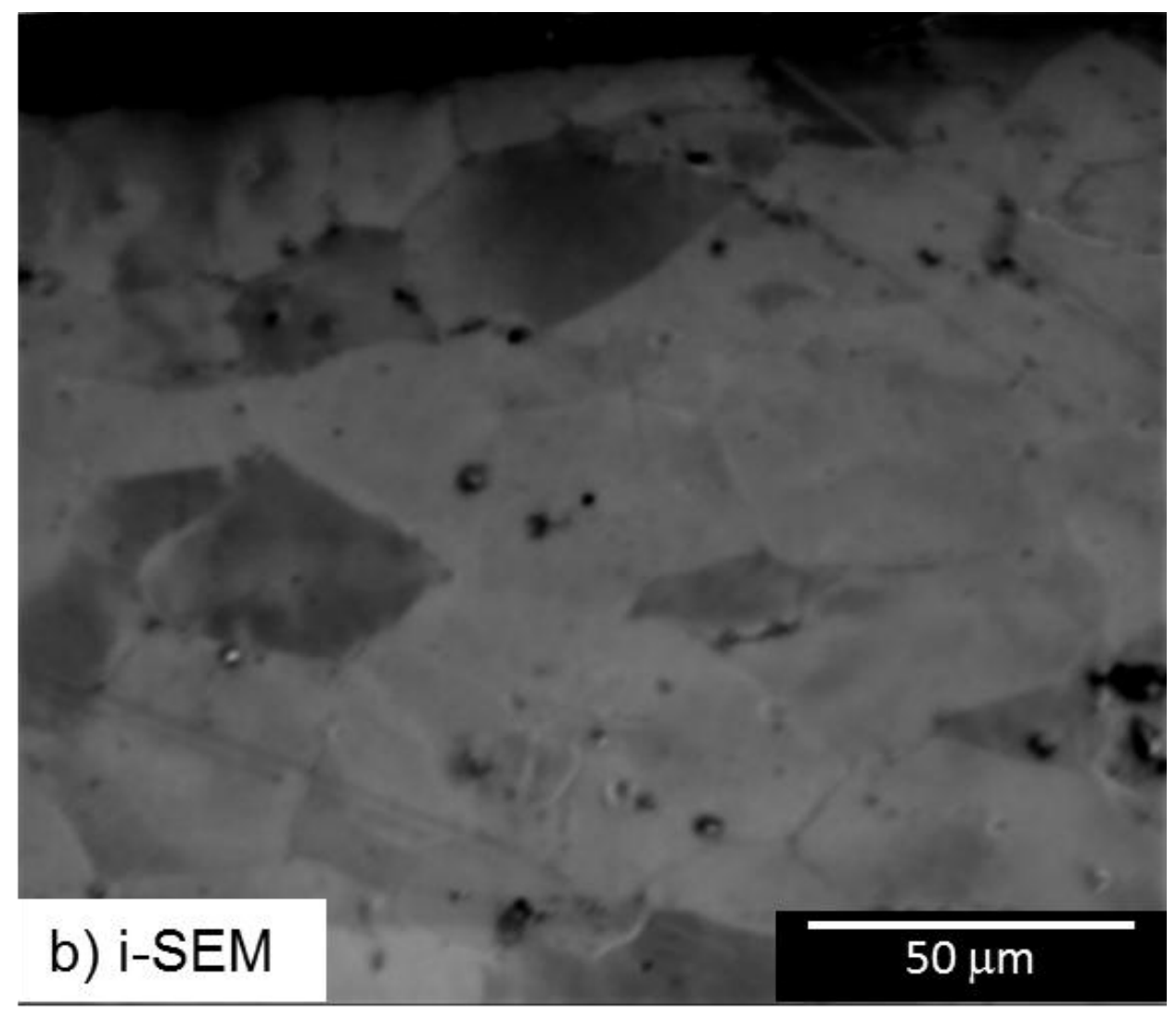

Figure 6 (b) 
Slice \#1

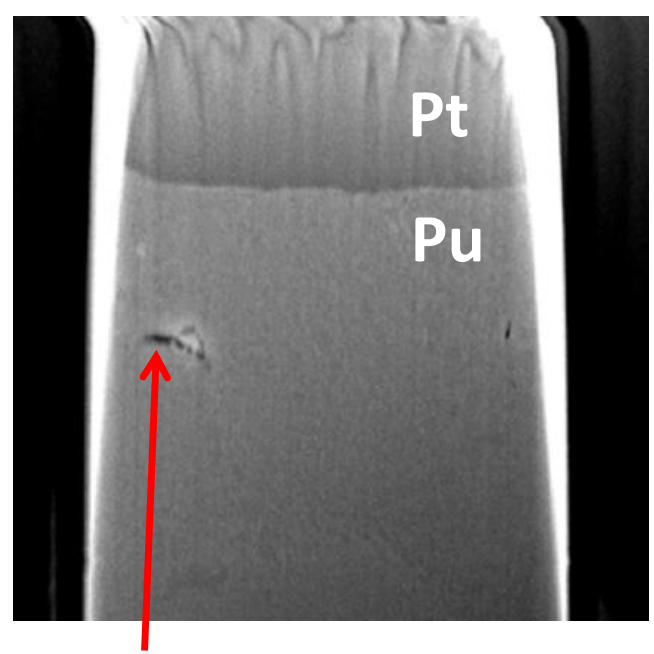

Pore and carbide inclusion

Slice \#170

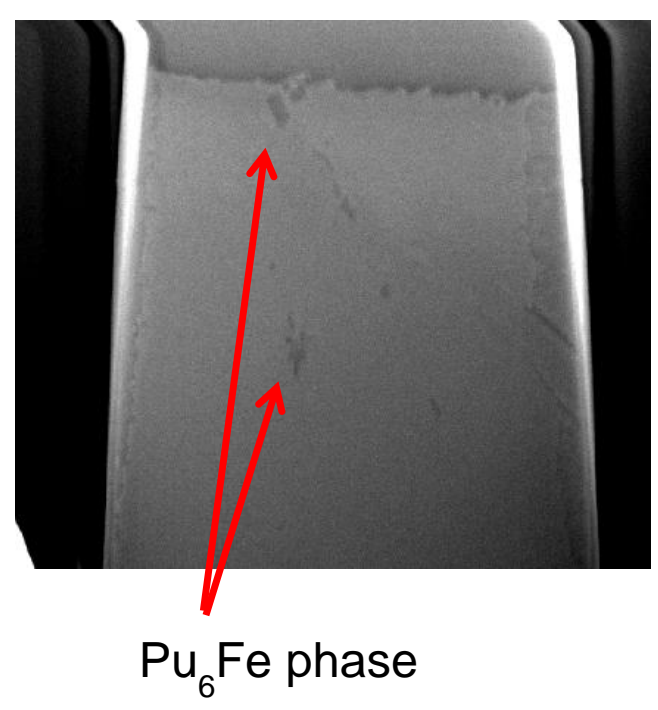

Slice \#70

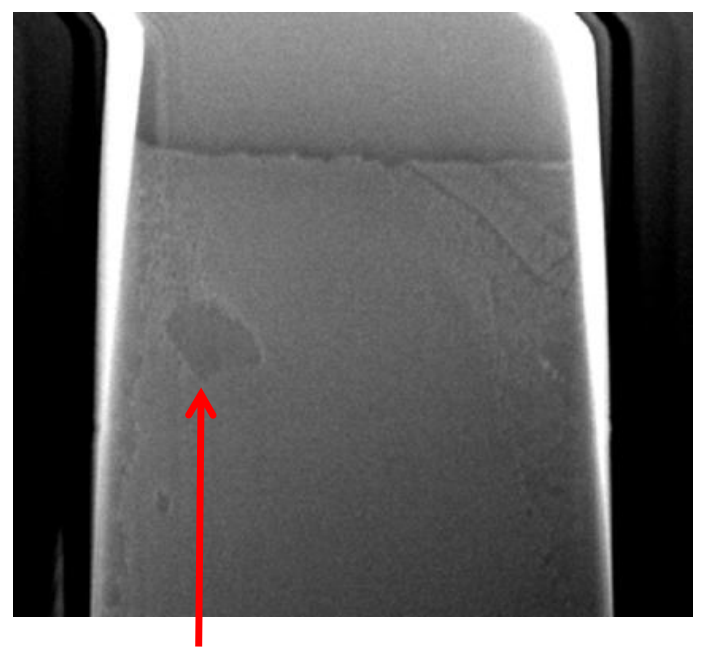

Carbide inclusion

Slice \#259

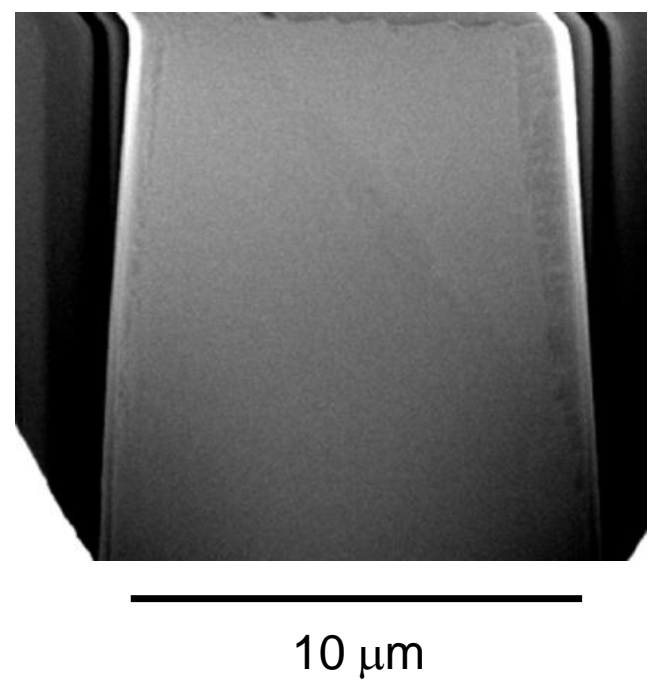

Figure 7 (a) 

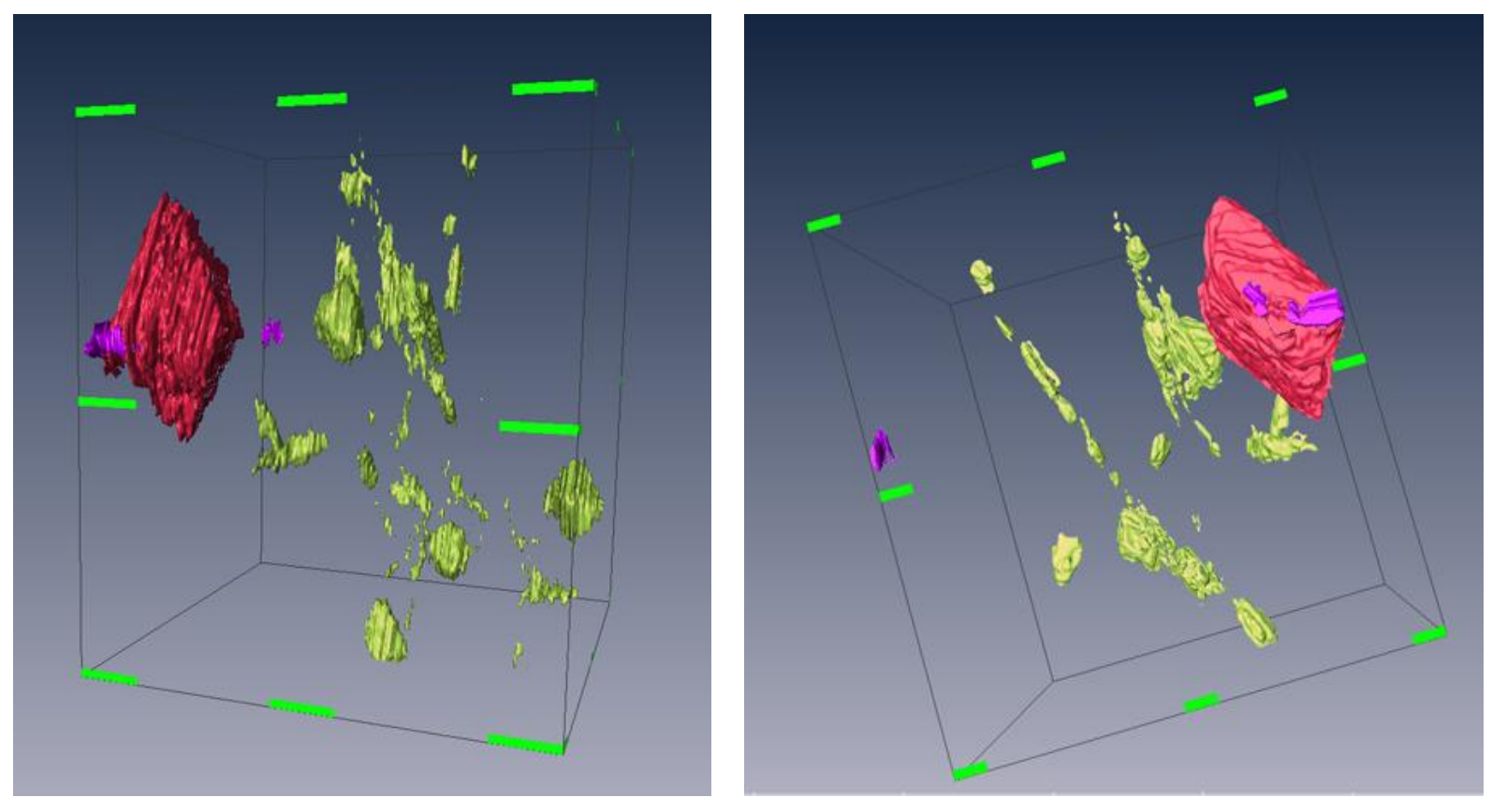

Figure 7 (b) 
Slice \#1

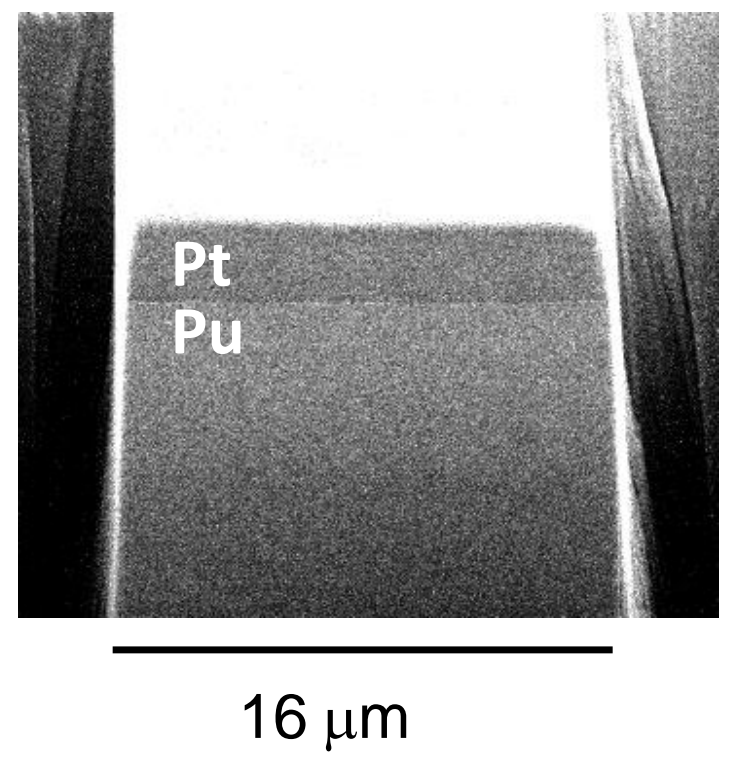

Slice \#70

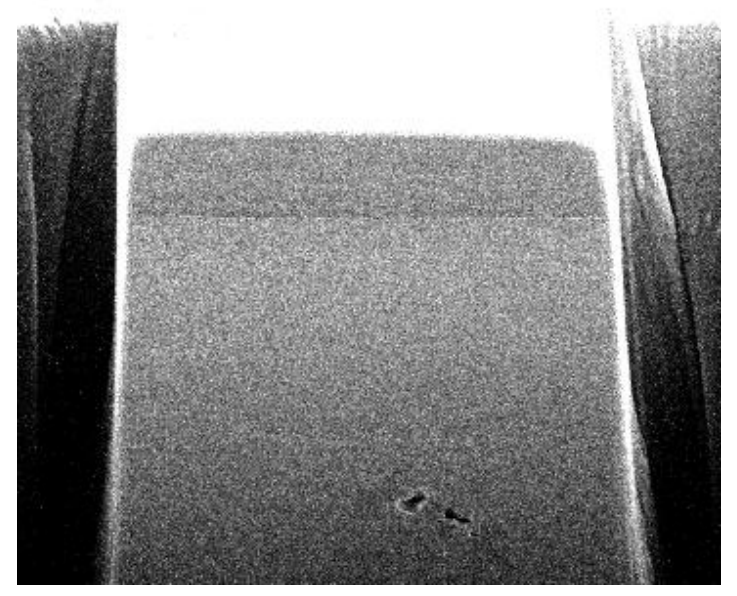

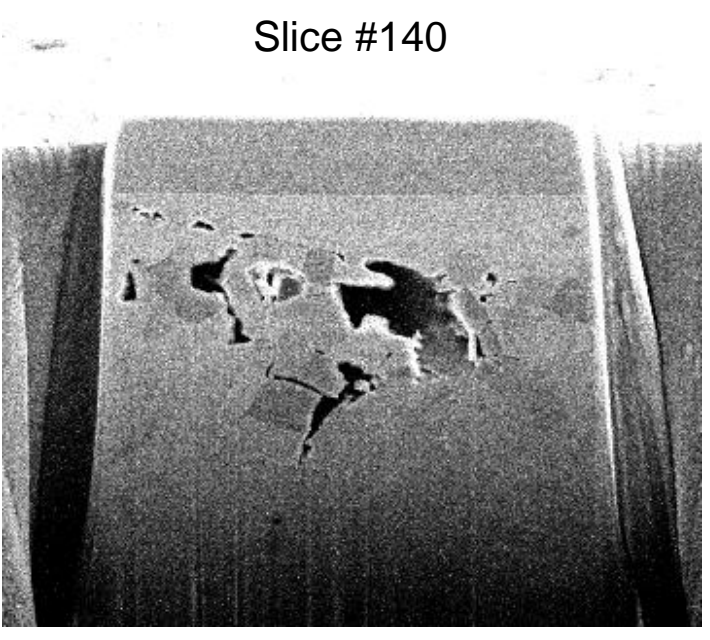

Figure 8 (a) 

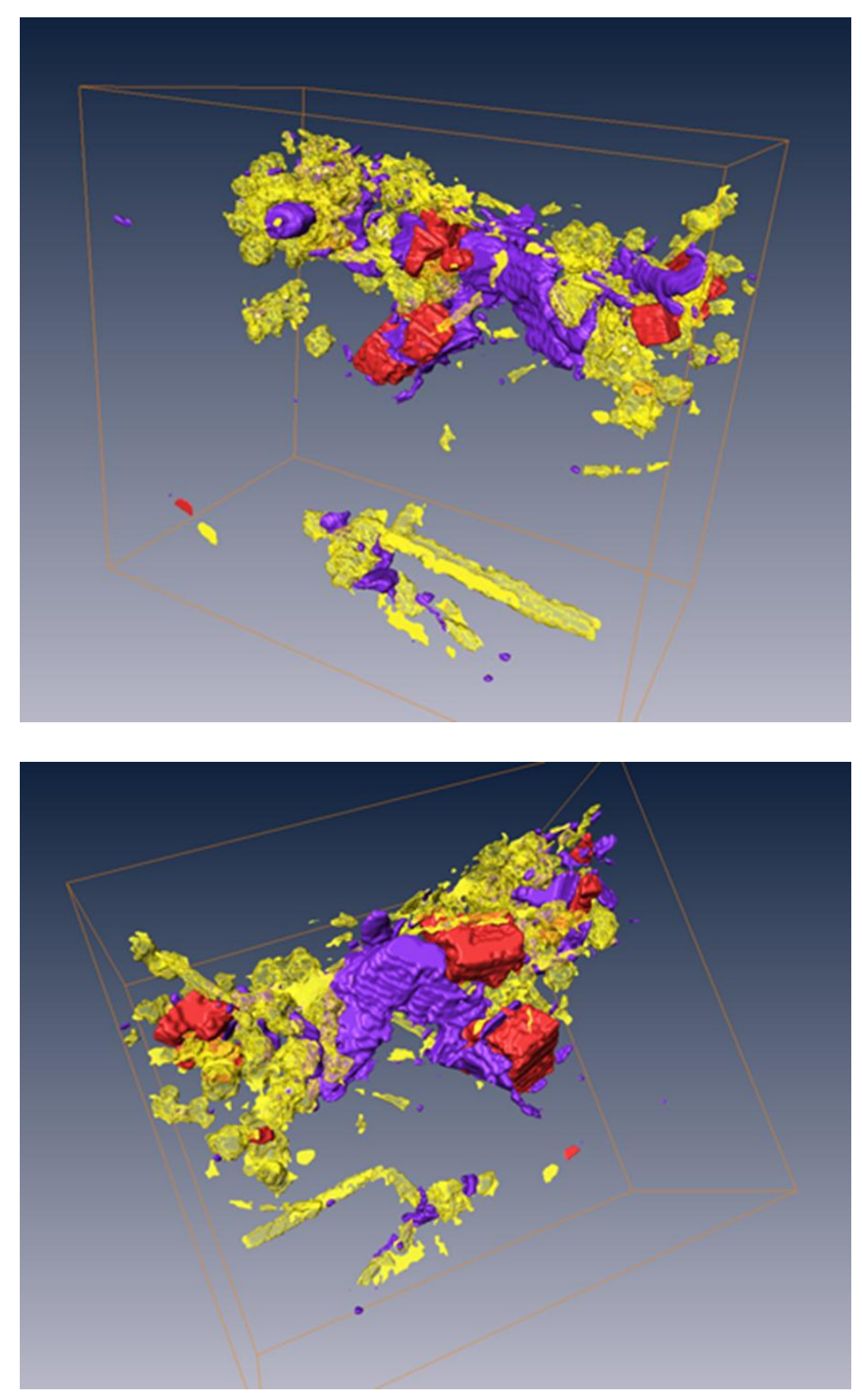

Figure 8 (b) 


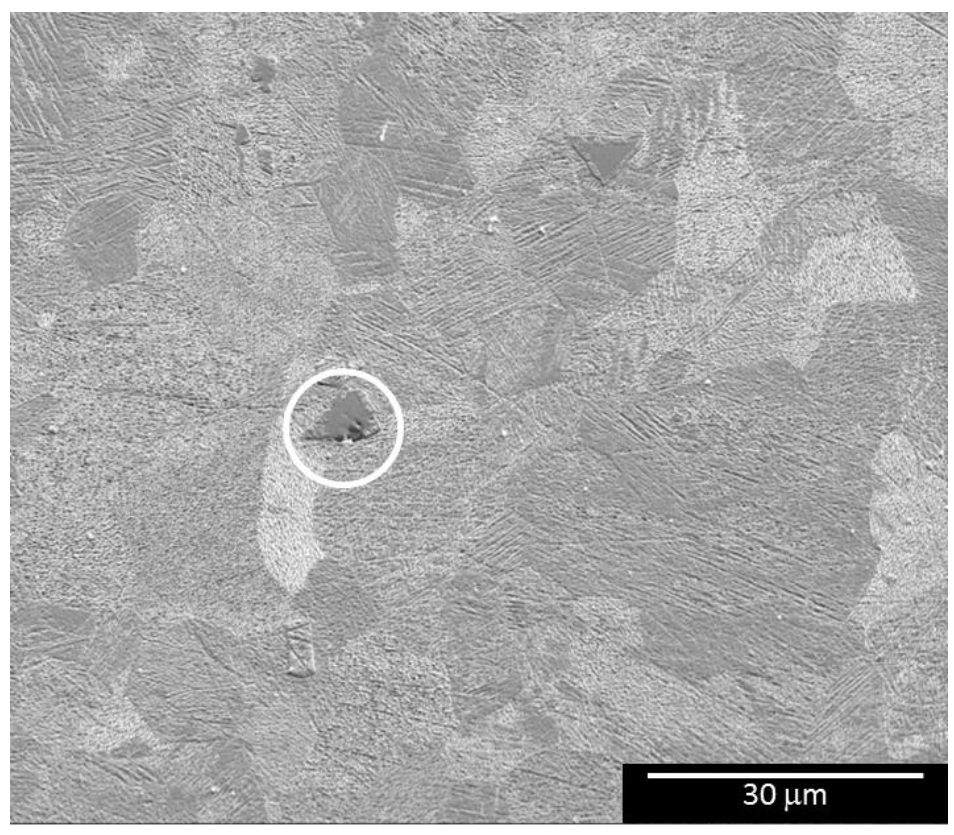

Figure 9 (a) 


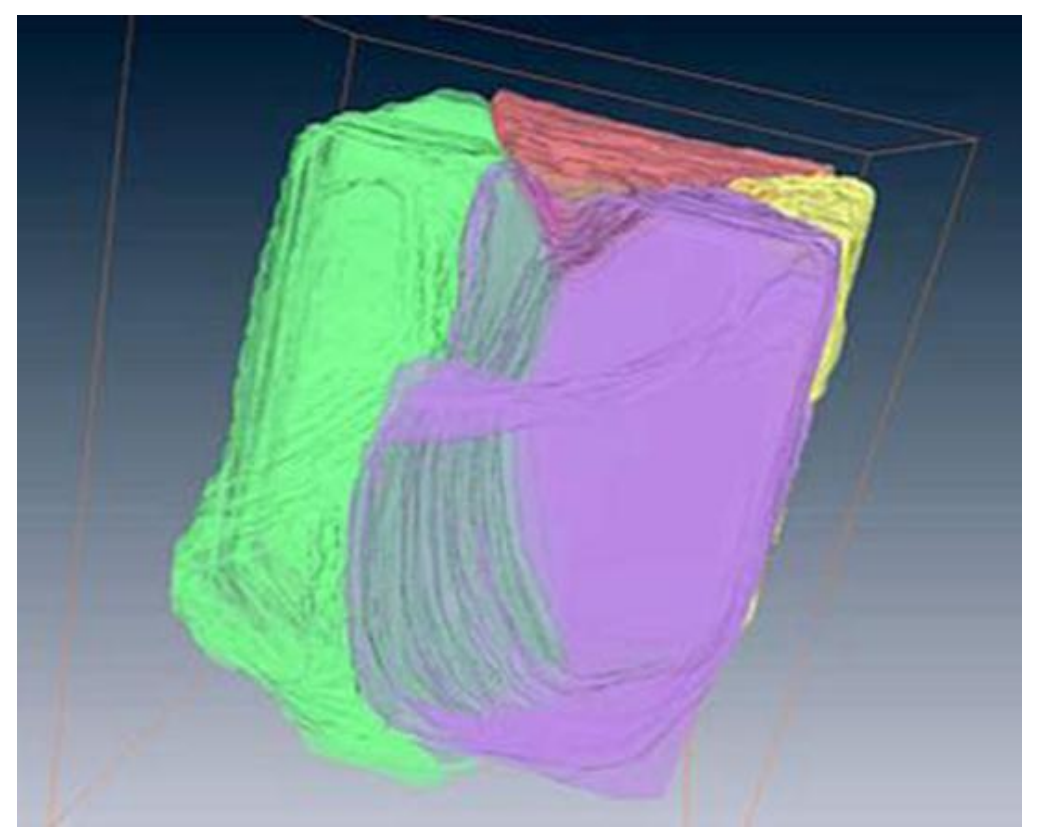

Figure 9 (b) 